\title{
Global competitive intelligence practice
}

\author{
Marié-Luce Muller \\ Managing Director and CI Analyst \\ IBIS Business and Information Services \\ mlm@ibis.co.za \\ www.ibis.co.za
}

\section{Introduction}

The annual publication of the World Economic Forum's Global Competitiveness Index (WEF 2007) and the IMD's World Competitiveness Yearbook (IMD 2007) highlight South African competitiveness. Another research project, the Doing Business project of the World Bank-IFC (World Bank/IFC2007), provides indicators on the competitiveness of South Africa and business in South Africa compared to 177 other countries. More specifically, it provides the objective measures of business regulations and states how they are implemented. When comparing the results of the aforementioned projects at first glance, it becomes clear that South Africa as a country and, by extension, South African business are seemingly caught in a competitiveness trap and are unable to meaningfully improve on their position year by year.

Over the past few years, the annual indices indicate the most prominent challenges that South Africa faces in terms of competitiveness, namely crime, unemployment, skills and bureaucracy. Although Africa, as an entity, has improved in ranking from last to third place in the latest Doing Business rankings, the report also points out that there remains much that can be done to enhance competitiveness and the ease of competing globally. The report found that, although Africa performed well in reforming aspects in the business climate, it still lags behind other regions in its overall rankings under the Doing Business index (World Bank 2007).

The IMD World Competitiveness Yearbook analyses and ranks the ability of nations to create and maintain an environment that sustains the competitiveness of enterprises. The 2007 IMD World Competitiveness Yearbook (IMD 2007) reveals that South Africa's rankings dropped from 38th position to 50th position out of 55 countries. Weaknesses indicate that improvements are needed in terms of discrimination that hinders economic development, personal security and private property protection, exchange rate stability and labour regulations that hinder business activities.

The overall results in the 2007 edition of the World Competitiveness Yearbook (2007) highlight the fact that competition among economies is becoming fiercer and that the gap between the fast movers and the followers is increasing. It is also clear that the traditional leaders, such as the United States and Singapore, cannot become complacent, as there is stiff competition from emerging nations such as China, Russia, India and Hong Kong.

The World Economic Forum's Global Competitiveness Index similarly shows a decline in South Africa's rankings from 36th position in 2006 to 44th in 2007.

\section{Impact on the competitiveness of business}

The competitiveness indices highlight the reality that businesses face, namely that there are 
many events in the external business environment that have an influence and impact on business. Businesses have to manage this impact efficiently to remain competitive (McCarthy 2007). Events and issues influence one another and McCarthy (2007) cites the example of unit labour cost as an important determinant of competitiveness and of how South Africa lags behind in this field owing to far lower unit costs in competitive economies, most notably those of Asia. McCarthy says: 'Unit labour cost is a function of productivity and wage levels. However, you cannot have wage levels that do not reflect the relative scarcity of labour, comparatively poor productivity performance that does not redress the impact of wage cost on unit labour cost, a liberalised trade environment and diversifying industrial growth. Something must give, most probably industrial activity.' This quotation emphasizes the fact that events affect one another and should be examined as a whole and not in isolation.

South African businesses in various sectors therefore have to deal with factors that are often not within their power of influence in order to compete on an even playing field. Players in the mining sector are a case in point. Mining lawyer Peter Leon (2007) says that growth is being impaired in the mining industry due to the existing regulations and legal uncertainty, such as the slow pace in granting licenses, failure by government to introduce clear licensing requirements and the cost of complying to the regulations. Players in the industry are affected, as foreign investment is discouraged.

Another industry that seems to bombard its players on an almost daily basis with significant events that need to be noted, is the financial services industry. Developments, including compliance with the Financial Services Charter (FSC), growing competition, new partnerships, the drive for organic growth, growth prospect on the African continent and the threat of new entrants (foreign and local), coupled with the increasing blurring of industry lines, emphasize the fact that it is imperative for companies to be constantly informed and forewarned of changes so as to be ready to respond to change, think creatively and know what should be done. Some events published recently that illustrate this point include Nashua Mobile, that recently branched into short-term insurance (ITWeb 2007) by forming a subsidiary to provide insurance products underwritten by Auto \& General; and the Shoprite Group and Old Mutual partnership to bring an innovative top-up insurance product called Pay-when-you-can, using Shoprite supermarkets in South Africa as a channel. Such partnerships are an increasingly regular occurrence with companies exploiting synergies to optimize operations. Old Mutual and Auto \& General benefit from the retailers' market access and brand while Nashua and Shoprite are diversifying their revenue streams (ITWeb 2007).

Another case illustrating the merging of industries, is the partnership between Microsoft and Imagination, a South African start-up company that will provide life insurance, banking and healthcare services to a market that is unable to participate in traditional financial services. A fully scalable IT system based on Microsoft technology, enables Imagination to offer a lowcost financial product to a price-sensitive market segment that is inadequately serviced in terms of financial products. In particular, Microsoft SQL Server has been deployed to manage important client information and monitor customer accounts, which are both important sets of information that, if used effectively, can enhance competitiveness. It offers the company the ability to react quickly to market changes by enabling it to rapidly adapt to these changes and exploit opportunities.

The aforementioned emphasizes two key aspects, namely the need to be able to react swiftly, decisively and accurately to market changes and the importance of information on the competitive environment. Fahey (1999) accurately described modern competition in the business environment as being characterized by the following: 'Any strategy is allowed unless it is against the law; new entrants may join the competition from anywhere anytime 
and may form alliances overnight; and the route and finish line may change after the race has started' (Fahey 1999).

What can companies that are experiencing difficulty in managing information, yet are starving for meaningful insights, do in this era of hyper-competition (Steyn 2007)? The volumes of information that have become increasingly difficult to manage and are no longer a resource in a company, have become the enemy (Naisbitt and Aburdene 1990). Bill Gates (1999) states that the ability to manage, gather, interpret and apply information would provide companies with a competitive edge and 'put distance between you and the crowd'.

In such an uncertain competitive environment, with an over abundance of information, and faced with rapid changes, how can companies stay abreast of issues and ahead of the competition? One of the most important tools would be to develop the ability to remain informed of developments in the external competitive environment on a continuous basis and, even more important, to have the ability to translate the interpreted information into meaningful action steps. CI is such a tool that now, more than ever before, can empower companies to not only remain informed of events but to also be able to anticipate change and devise strategies to manage change amid pressure to manage cost, grow market share and increase the return on investment.

CI is a simple, effective tool to assist companies to find ways to gather and interpret information and communicate the intelligence in meaningful ways to key decision makers to enable them to make sound business decisions. If done well, CI will provide a glimpse into how the future may unfold, what opportunities may be presented and which threats to avoid. Knowledgement management and the use of increasingly sophisticated business intelligence tools will assist in this endeavour, but there is no substitute for human insight, which is unique. This is where CI plays an important decisive role in providing insight into a particular future and interpreting information to identify a particular event's impact on a particular company and to provide particular tailored advice on the way forward. The challenge lies in obtaining information, verifying its authenticity, interpreting its impact and meaning and using it timely and effectively.

CI can be broadly defined as a multidisciplinary process that has become the pre-condition for survival for companies as well as national economies (Rodenberg 2007). CI is the process of examining the external competitive environment, including direct rivals, customers, suppliers, economic/regulatory issues and more - to support the development of more resilient, robust strategies and tactics (Correia 2006). The results of the intelligence should be meaningful and actionable (have the clarity to make actions easy). CI should focus on providing insight into change and developments, impacting the business and providing clear and simple guidance for possible action steps (Gilad 1996; SCIP 2007). It is first and foremost a strategic management tool. By definition, intelligence is intended to support decisions and actions, minimize the risks and/or maximize the opportunities surrounding future actions (Correia 2006).

\section{Conclusion}

The case for CI has not diminished over the past ten years. On the contrary, for reasons already mentioned, it is a tool that has become indispensable, especially against the background of the need for enhanced competitiveness, clearly shown in various competitiveness indices and research.

CI is widely practised in South Africa, although the manner in which CI is conducted differs from company to company. Some have comprehensive capabilities while other, often smaller companies, resort to outsourcing some aspects of CI. Although it is clear that businesses in 
South Africa have acknowledged the importance of doing an 'outstanding job with information' (Gates 1999), CI practices can improve and become more sophisticated and effective. CI is not only beneficial for business but can also be similarly used by all levels of government. For example, foreign investment and tourism spend and ultimately promote the competitiveness of South Africa as a country. It is a competitiveness tool that is enhanced by the use of business intelligence tools.

Previous columns provide further useful insights into CI and how it can be applied to enhance competitiveness.

\section{References}

Correia, C.C. 2006. Competitive intelligence: a practical primer for location intelligence. Directions Magazine 21 February.

Fahey, L. 1999. Competitors, outwitting, outmaneuvering, and outperforming. John Wiley \& Sons, Inc.

Gates, W.H. III. 1999. Business @ the speed of thought: using a digital nervous system.

Gilad, B. 1996. Business blindspots: replacing myths, beliefs, and assumptions with market realities.

IMD. 2007. World competitiveness yearbook. Available: www02.imd.ch/wcy.

ITWeb. 2007. Nashua Mobile rolls out insurance. Available: www.itweb.co.za

Leon, P. 2007. Mining regulations damaging growth. South African Institute of Race Relations (SAIRR), Johannesburg.

McCarthy, C. 2007. Competitiveness of South African firms. Tralac newsletter. November. Available: http://www.tralac.org/newsletter/07nov2007.html.

Naisbitt, J. and Aburdene, P. 1990. Megatrends 2000.

Steyn, C. 2007. Creative leadership for a competitive advantage in the knowledge economy. Leader. Available: http://www.leader.co.za/article.aspx?s=1\&f=1\&a=332.

WEF. 2007. Global competitiveness report. Available: www.weforum.org/en/initiatives/gcp/Global\%20Competitiveness\%20Report/idex.

World Bank - IFC. 2007. Doing Business Report 2007. Available on the Internet: http://www.doingbusiness.org/documents/2006-MENA.pdf.

\section{About the author}

Marié-Luce Muller is a consulting CI analyst with IBIS Business and Information Services (Pty) Ltd, a leading Pretoria-based CI consultancy. She has a distinguished career in CI. Her primary experience lies in assisting companies in honing their CI capabilities. She also performs tracking and scanning activities on behalf of companies. Marié-Luce has published many articles on competitive intelligence (CEO Magazine, Finance Week, Business Week, Beeld, Die Burger and the South African Journal of Business Management), including an article on South Africa as an emerging CI player, which was published in an international publication of the Society of Competitive Intelligence Professionals (SCIP). She has also published a series of booklets on CI (Nuts and Bolts business series, published by 
Knowledge Resources) and is a member of a research team participating in an international study of CI practices among exporting companies. Previously, she was involved in research into the status of CI practices in South Africa. A member of SCIP, she holds a postgraduate degree from the University of Stellenbosch.

ISSN 1560-683X

Published by InterWord Communications for Department of Information and Knowledge Management, University of Johannesburg 